\title{
EDUCAÇÃO FINANCEIRA NO ENSINO MÉDIO: POSSIBILIDADES
}

\section{FINANCIAL EDUCATION IN HIGH SCHOOL: POSSIBILITIES}

\author{
Danilo Pontual de Melo ${ }^{1}$ \\ Cristiane Azevêdo dos Santos Pessoa ${ }^{2}$
}

\begin{abstract}
Resumo: O presente artigo é o recorte de um estudo de mestrado que buscou compreender possibilidades de abordagem da Educação Financeira (EF) relacionada com a Matemática Financeira, a partir de um grupo de estudo com professores de Matemática no Ensino Médio. Utilizamos como fundamentação teórica a Educação Matemática Crítica de Skovsmose (2000). No recorte apresentado neste texto, objetivamos discutir como podemos abordar a EF no Ensino Médio, a partir da experiência vivenciada pelos professores participantes da pesquisa. Os resultados mostram a importância de se trabalhar com dados reais nas discussões de sala de aula e que os professores e os estudantes trabalharam com uma EF ampla e subjetiva, que não envolve apenas a Matemática e as questões financeiras e econômicas. Concluímos que a EF possui um caráter para além da discussão no campo matemático, é preciso que sua abordagem aconteça visando à formação de sujeitos críticos.
\end{abstract}

Palavras-chave: Educação Financeira; Educação Matemática Crítica; Professores; Ensino Médio.

\begin{abstract}
This article is a cut of a master's study that tried to understand possibilities of approach to Financial Education (EF) related to Financial Mathematics, from a study group with teachers of Mathematics in High School. We use as theoretical foundation the Critical Mathematical Education of Skovsmose (2000). In the section presented in this text, we aim to discuss how we can approach EF in High School, based on the experience of the teachers participating in the research. The results show the importance of working with real data in classroom discussions, that teachers and students have worked with a broad and subjective EF, which involves not only Mathematics and financial and economic issues. We conclude that EF has a character beyond the discussion in the mathematical field, it is necessary that its approach happens aiming at the formation of critical subjects.
\end{abstract}

Keywords: Financial Education; Critical Mathematics Education; Teachers; High school.

\section{Introdução}

Nossa sociedade torna-se cada vez mais complexa em diversos aspectos, um deles é o financeiro, a cada dia bancos e instituições financeiras utilizam estratégias variadas para atrair consumidores de bens e serviços, que muitas vezes estão passando por problemas no campo econômico. Buscamos investigar como a Educação Financeira (EF)

\footnotetext{
${ }^{1}$ Mestre em Educação Matemática e Tecnológica pela Universidade Federal de Pernambuco (UFPE). Professor da Rede Estadual de Ensino de Pernambuco (SEDUC), Gravatá, Pernambuco, Brasil. E-mail: danilopontualufpe@gmail.com

${ }^{2}$ Doutora em Educação pela Universidade Federal de Pernambuco (UFPE). Professora do departamento de Métodos e Técnicas de Ensino e professora do Programa de Pós-Graduação em Educação Matemática e Tecnológica da Universidade Federal de Pernambuco (UFPE), Recife, Pernambuco, Brasil. E-mail: cristianepessoa74@gmail.com
} 
DOI: http://dx.doi.org/10.33238/ReBECEM.2019.v.3.n.2.22536

pode ser desenvolvida na educação básica, de modo que o estudante possa refletir e discutir sobre a temática desde cedo. No entanto, é importante destacar que aqui trataremos da Educação Financeira Escolar (EFE), que além de contemplar o campo financeiro, está preocupada também com os outros aspectos envolvidos no processo de tomada de decisão, tais como as influências das propagandas, as questões ambientais, políticas, sociais e éticas, entre outras.

A Organização para a Cooperação e desenvolvimento Econômico (OCDE) promove e incentiva que os seus países membros e países parceiros desenvolvam programas de educação fincnaceira. Esta organização atua, dentre outras ações, por meio da realização de fóruns anuais que buscam promover políticas públicas entre os países mais ricos, visando ao desenvolvimento e à expansão econômica das nações integrantes, com o objetivo de fortalecer a economia global.

O Brasil não é um país membro da OCDE, faz parte do grupo dos países parceiros da organização e, inpirado pelo trabalho de expansão da educação financeira no mundo, estabelece a Estratégia Nacional de Educação Financeira (ENEF). Com o objetivo de contribuir para o fortalecimento da cidadania e assim auxiliar as pessoas na tomada de decisões financeiras autônomas e conscientes, é resultado da articulação entre governo, sociedade civil e iniciativa privada. No entanto, alguns estudos criticam o posicionamento mercadológico, bancário e voltado às finaças que a ENEF propõe.

Santos e Pessoa (2016) ressaltam que a EF é algo recente no Brasil e, portanto, deve ser discutido e investigado, principalmente se pensarmos na forma como a EF é abordada na educação básica. É importante que a EF oferecida conduza o estudante ao desenvolvimento de uma postura crítica diante de situações financeiras, auxiliando na tomada de decisões concientes e responsáveis em sua atuação, enquanto ser social.

Entendemos que a EF deve ser abordada a partir de um olhar crítico e reflexivo por parte dos estudantes. Estabelecemos, portanto, aproximações com as preocupações estabelecidas por Skovsmose (2000) na Educação Matemática Crítica (EMC). O autor discute o papel social, político e econômico da Matemática, colocando-a como ferramenta de investigação e estímulo à autonomia intelectual, assumindo a Matemática como meio de formatação da sociedade em que estamos inseridos.

Precisamos ter em mente que a EF oferecida nas escolas precisa estar preocupada com a formação integral dos estudantes, desde o domínio dos 
DOI: http://dx.doi.org/10.33238/ReBECEM.2019.v.3.n.2.22536

conhecimentos básicos envolvidos até o papel político, social, ambiental, psicológico entre outros que estão envolvidos no processo de ensino e aprendizagem.

O presente artigo é parte de um estudo de mestrado ${ }^{3}$ (Melo, 2019), que teve como objetivo geral compreender possibilidades de abordagem da EF relacionada à MF a partir de um grupo de estudo com professores de Matemática do Ensino Médio. Neste texto, objetivamos discutir como podemos abordar a EF na sala de aula do Ensino Médio, a partir da experiência vivenciada pelos professores participantes da pesquisa maior, de mestrado.

A seguir, tratamos de forma mais detalhada a respeito da EF do ponto de vista escolar e discussões de autores da área, com o objetivo de refletirmos a respeito de possibildades de aproximar a EF cada vez mais do ambiente escolar.

\section{Educação Financeira}

A EF é uma temática recente, principalmente no campo educacional. Por muito tempo o assunto foi tratado apenas por instituições financeiras, privadas ou públicas, por consultores financeiros que orientam a população acerca do uso do dinheiro visando a evitar o endividamento e consequentemente o comprometimento da renda.

Muniz e Jurkiewicz (2013) apontam a necessidade que o tema seja tratado devido à falta de conhecimento financeiro da população em sua maioria. Segundo os autores, a EF vem sendo alvo da discussão de diversos agentes: 1) agentes governamentais; 2) agentes de instituições financeiras privadas; 3) consultores financeiros; 4) pesquisadores e professores de Matemática.

Os agentes governamentais, a partir da OCDE, desenvolvem ações de EF. No Brasil o que temos de mais recente é a ENEF, com a finalidade de promover a EF e previdenciária a partir de políticas de inclusão social no país. Inicialmente o público atendido pela ENEF foram os jovens, por meio de ações nas escolas, aposentados e mulheres beneficiárias do programa Bolsa Família.

Os autores também apontam os agentes de instituições financeiras privadas que são os que mais promovem ações educativas relacionadas aos temas financeiros, com foco na orientação e consumo de seus produtos financeiros, as quais convergem para seus interesses e de acordo com a conveniência de suas atividades, para atingir objetivos geralmente bem particulares.

\footnotetext{
${ }^{3}$ Elementos da dissertação são retomados no presente artigo.
} 
DOI: http://dx.doi.org/10.33238/ReBECEM.2019.v.3.n.2.22536

Segundo eles, os agentes de instituições financeiras privadas são os

[...] que mais promovem ações "educativas" relacionadas aos temas financeiros, com foco na orientação e consumo de seus produtos financeiros, as quais convergem para seus interesses e de acordo com a conveniência de suas atividades, para atingir objetivos geralmente bem particulares (MUNIZ; JURKIEWICZ, 2013, p. 2).

Existe ainda um terceiro grupo de agentes, o dos consultores financeiros, facilmente encontrados em programas de jornais, rádio e TV, funcionando como uma espécie de autoajuda financeira para o público do respectivo meio de comunicação.

Acreditamos que a EF na qual se fundamenta a OCDE e os agentes financeiros privados não possibilitam o desenvolvimento de uma consciência mais crítica e reflexiva pelos alunos e professores acerca das questões financeiras, essa perspectiva, de um modo geral, estimula o consumo, pois orienta que as pessoas organizem suas finanças pessoais para que possam consumir os produtos oferecidos.

Mesmo com a implementação da ENEF, acreditamos que a forma como a EF vem sendo abordada nas escolas ainda necessita de um processo de aprimoramento e adequação pedagógica. A EFE não pode ser abordada na mesma perspectiva da EF de bancos e instituições financeiras, para que os estudantes são sejam envolvidos apenas em discussões sobre poupar para realizar sonhos de consumo ou em um processo de resolução de cálculos financeiros, sem o desenvolvimento de uma discussão crítica dos aspectos sociais, ambientais, políticos e éticos envolvidos.

O quarto e último grupo de agentes que Muniz e Jurkiewicz (2013) destacam é formado pelos professores e pesquisadores da Educação Matemática que precisam tratar de questões financeiras na sala de aula, ou seja, buscam na EF o seu viés pedagógico, já que a EF apresentada pelos demais agentes busca em sua maioria satisfazer seus interesses próprios, que a EF apresentada por consultores financeiros também não satisfaz o público educacional pois não se preocupa com sua natureza pedagógica. A partir do quarto agente financeiro elencado por Muniz e Jurkiewicz (2013) adotamos aqui a ideia da Educação Financeira Escolar (EFE).

É nesse grupo que estamos inseridos e buscamos discutir a EFE, ou seja, estamos preocupados com o processo de ensino e aprendizagem que acontece quando abordamos a temática em sala de aula. Isso não quer dizer que estamos retirando a importância das perspectivas que os outros agentes empregam à EF, apenas não coadunamos com a perspectiva de que seja abordada no ambiente escolar apenas no viés do poupar para conseguir alcançar objetivos futuros, pois esta pode até ser uma EF mais voltada para os 
DOI: http://dx.doi.org/10.33238/ReBECEM.2019.v.3.n.2.22536

adultos que já possuem uma visão mais estruturada de mundo, mas não para crianças e jovens estudantes.

Acreditamos que a EF acontece de forma eficiente se os indivíduos recebem essa formação durante sua vivência escolar, assim a EF chega às escolas e se torna objeto de investigação de pesquisas acadêmicas das áreas de Educação e de Educação Matemática, com o objetivo de compreender como vem sendo abordada nas escolas e em quais aspectos o trabalho com a temática precisa melhorar.

No trabalho com a EFE devemos ir além de aprender a economizar, cortar gastos, juntar dinheiro, devemos buscar a promoção de reflexão e compreensão de habilidades e conhecimentos acerca de consumo, ética, influência da mídia e das propagandas, preservação do meio ambiente, valor dos produtos, entre outras questões presentes na nossa vida em sociedade.

Nesse sentido, Pessoa, Muniz e Kistemann Jr. (2018) apontam a importância do caráter crítico da EF. Segundo eles, não convém realizar uma abordagem da EF desconectada da realidade dos estudantes, em que sejam levados a solucionar uma situação hipotética de consumo, que em nada se aproxima de sua vivência social.

\section{[...] a resolução de um exercício sem uma discussão crítica dos temas presentes, com uma mediação docente preparada para fomentar discussões, questionamentos e novas pesquisas sobre o tema, acaba por impedir a gênese de ambientes de aprendizagem e pesquisa que proporcionariam o desenvolvimento da Literacia Financeira. Em outros termos, resolve-se uma tarefa, mas, meramente, para, a partir de alguns dados, encontrar-se uma resposta desconectada da realidade econômica daquelas que solucionaram (certo ou não) a tarefa (PESSOA; MUNIZ; KISTEMANN JR., 2018, p. 9).}

Coutinho (2016) também aponta a necessidade de que a EF seja abordada para além do enfoque procedimental. Segundo a autora, devemos realizar uma "abordagem conceitual, que não se detém nos resultados de cálculos, mas avança para a análise crítica destes resultados, considerando o contexto no qual os dados foram coletados" (COUTINHO, 2016, p. 1).

Coadunamos com o que defendem os autores anteriormente citados, é preciso conferir à EF oferecida na escola uma abordagem em que o estudante possa refletir, discutir e analisar diferentes perspectivas, ampliando seu campo de conhecimento financeiro. Para tanto, é necessário questionar e modificar a crença de que trabalhar a EF na escola é trabalhar apenas os procedimentos dos cálculos financeiros.

Em relação ao conceito da EFE, assumimos aqui o proposto por Silva e Powell (2013), quando definem que: 
DOI: http://dx.doi.org/10.33238/ReBECEM.2019.v.3.n.2.22536

A Educação Financeira Escolar constitui-se de um conjunto de informações através do qual os estudantes são introduzidos no universo do dinheiro e estimulados a produzir uma compreensão sobre finanças e economia, através de um processo de ensino que os torne aptos a analisar, fazer julgamentos fundamentados, tomar decisões e ter posições críticas sobre questões financeiras que envolvam sua vida pessoal, familiar e da sociedade em que vivem (SILVA; POWELL, 2013, p. 12).

Os pesquisadores Silva e Powell (2013) destacam a preocupação com a presença de instituições financeiras privadas na elaboração do Programa Educação Financeira nas Escolas, desenvolvido como projeto piloto pela ENEF, segundo eles, isso retira o caráter pedagógico do projeto, essas instituições podem estar, na realidade, buscando satisfazer condições melhores para si próprias e não para o bem comum da sociedade.

A preocupação levanta pelos autores aponta para a falta de um processo de formação com os professores que são os responsáveis por fazer com que a EF seja efetivamente abordada em sala de aula, apenas a disponibilidade do material para download ainda é muito pouco se desejamos realmente que esse trabalho aconteça de forma estruturada e consciente.

E sobre o trabalho com a EF nas escolas, Oliveira (2017) aponta a importância de um olhar crítico pelos professores no trabalho com a EFE através do desenvolvimento de uma postura reflexiva.

Compreendemos que, embora a proposição de políticas públicas que buscam promover a inserção da EF no ambiente escolar seja um aspecto muito positivo, aceitar todas as suas orientações sem reflexão, tendo em vista a influência de diversos setores da sociedade (além da educação), como o setor financeiro representado pelos bancos, seria no mínimo contraditório ao que estamos defendendo por EF, uma educação que, dentre outros pontos, preocupa-se em desenvolver uma consciência mais crítica e reflexiva pelos alunos e também pelos professores, no sentido de compreenderem as possibilidades de decisões que podem tomar frente às situações de consumo, ponderando as vantagens e desvantagens de cada escolha, de acordo com as suas situações econômicas (OLIVEIRA, 2017, p. 20).

O olhar crítico que deve ser empregado à EFE deve envolver a realidade dos estudantes, de modo que eles consigam perceber a necessidade de dominar tal conhecimento acerca da EF, como apontam, Kistemann Jr., Almeida e Ribeiro (2017). Segundo Silva e Powell (2015) devemos iniciar o trabalho com a EF desde cedo nas escolas, considerando o fato de que quanto mais cedo as pessoas forem educadas financeiramente, mais aptas a lidar com situações financeiras e de tomadas de decisão elas estarão.

Sobre a importância de se trabalhar a EFE, Campos (2013) destaca que todos nós, desde a infância, temos disponíveis diversos bens e serviços. E essa vivência se torna 
DOI: http://dx.doi.org/10.33238/ReBECEM.2019.v.3.n.2.22536

ainda mais intensa quando se trata de jovens egressos da educação básica, que estão adentrando fortemente na administração de seus próprios orçamentos, que envolvem situações de tomada de decisão em relação ao seu dinheiro. Como estímulo para o consumismo, o apelo do marketing se torna cada vez mais intenso a cada dia, daí a importância que os estudantes tenham contato com discussões de cunho financeiro desde cedo nas escolas.

O domínio do conhecimento financeiro, como os autores apontam deve levar em consideração a realidade dos estudantes e não estar voltado apenas para pessoas que possuem um alto poder aquisitivo. Para Pessoa (2016), quanto mais a sociedade se complexifica, mais necessário é o domínio do conhecimento financeiro das pessoas de qualquer nível socioeconômico, que a compõem. Esse trabalho deve acontecer também e principalmente no ambiente escolar, para que todos possam ser capazes de analisar e tomar decisões criticamente na teia complexa em que a sociedade atual está estruturada.

Acerca do trabalho com a EFE, Oliveira (2016) destaca que, embora seja recente na perspectiva escolar, sua presença contribui de forma eficiente para uma formação crítica dos estudantes.

\begin{abstract}
Embora seja uma temática nova, sua importância vem sendo ressaltada, pois frente a um contexto social permeado por demandas de consumo, por mudanças nas relações sociais e modos de vida, em uma sociedade cada vez mais complexa e que exige do cidadão conhecimentos referentes a como lidar com o dinheiro, possibilidades de escolhas, armadilhas do consumismo, tomadas de decisão, reflexões sobre os conceitos de querer e de precisar, usos de produtos financeiros de modo consciente, dentre outros, torna-se indispensável a inserção de um trabalho com a EF nas escolas (OLIVEIRA, 2016, p. 2).
\end{abstract}

Encontramos aproximações entre as discussões de Bauman (2008) e o que defendemos como abordagem da EFE, em que os estudantes possam refletir sobre as armadilhas do consumismo, das criações falsas de necessidades (quando na verdade são desejos), da influência que a mídia, as propagandas e o marketing exercem em uma sociedade, da importância da preservação ambiental para a saúde do nosso planeta, dentre outras reflexões críticas. A respeito da relação de conumo, Coutinho e Teixeira (2015) destacam que deve acontecer de forma planejada, de modo que analisemos essa facilidade de crédito que encontramos, pois ela pode implicar no acúmulo de dívidas e descontrole da vida financeira.

No que diz respeito ao trabalho com a EFE, Muniz (2016) elenca quatro princípios que, segundo ele, devemos considerar ao levar a temática para a sala de aula: (1) Convite à reflexão - devemos permitir que os estudantes possam refletir sobre o processo de 


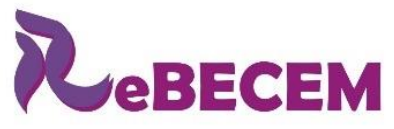

DOI: http://dx.doi.org/10.33238/ReBECEM.2019.v.3.n.2.22536

tomada de decisão que envolve a EF; (2) Conexão didática - a EFE deve ser abordada em uma perspectiva mais ampla que a adotada pelos agentes de instituições financeiras e consultores financeiros; (3) Dualidade - ao trabalharmos a EFE os estudantes devem compreender os conceitos e conteúdos matemáticos envolvidos e vice-versa; (4) Lente multidisciplinar - não devemos oferecer leituras puramente matemáticas das situações financeiras, o trabalho deve acontecer através de uma abordagem multidisciplinar.

No que concerne aos princípios elaborados por Muniz (2016), acreditamos que eles representam o mínimo de como a EFE deve ser tratada nas escolas, ou seja, não representam o ponto máximo de possibilidades, na verdade eles nos fazem refletir sobre caminhos que podemos percorrer no nosso trabalho dentro do ambiente escolar. O autor realiza uma importante contribuição, de forma clara e objetiva aponta para nós, professores, que a EFE vai muito além da EF de outros agentes financeiros. A EFE possui objetivos bem mais amplos e, portanto, maiores também são os desafios de se colocar em prática a EFE da forma a possibilitar a criticidade no processo de tomada de decisão.

A partir dos princípios elencados por Muniz (2016) a respeito da EFE, acreditamos que uma possibilidade para o trabalho com a EF nas escolas é a construção de uma relação entre a EF e a MF. Por exemplo, ao levarmos em consideração o princípio da dualidade, devemos possibilitar que ao explorar as situações da EF os estudantes também consigam compreender os conceitos matemáticos envolvidos e vice-versa, esses são principalmente conceitos da MF, como: capital, juros simples e compostos, montante, taxa de juros, variação percentual, dentre outros. Ao fazermos esta defesa, não descartamos a importância de aspectos não matemáticos no trabalho com a EFE, tais como questões ambientais, éticas, influências da mídia nas tomadas de decisão, desejos despertados pelas propagandas, dentre outros. Estes aspectos não matemáticos serão percebidos ao analisarmos as aulas que apresentaremos mais adiante, na seção de resultados.

$\mathrm{Na}$ seção a seguir, apresentamos as principais preocupações da Educação Matemática Crítica, nosso referencial teórico. 


\section{Educação Matemática Crítica}

A Educação Matemática Crítica (EMC) se preocupa em discutir a Matemática a partir de uma perspectiva social, política, econômica, entre outros aspectos que permeiam nossa realidade social, sendo assim ela objetiva a utilização da Matemática como ferramenta de investigação e estímulo à autonomia intelectual.

Skovsmose (2000) é um dos principais representantes da discussão acerca da EMC que, segundo o autor, "busca expressar certas preocupações a respeito da educação matemática" (SKOVSMOSE, 2014, p.10).

Da maneira como eu concebo a educação matemática crítica, ela não se reduz a uma subárea da educação matemática; assim como ela não se ocupa de metodologias e técnicas pedagógicas ou conteúdos programáticos. A educação matemática crítica é a expressão de preocupações a respeito da educação matemática (SKOVSMOSE, 2014, p.11).

A preocupação que Skovsmose (2014) destaca no campo da Educação Matemática diz respeito ao poder de despotencialização e potencialização dos alunos, consequência da forma como a Matemática é abordada durante as aulas.

Segundo Skovsmose (2014) a Educação Matemática despotencializa os alunos quando não considera os aspectos sociopolíticos envolvidos no processo de ensino e aprendizagem. Os exercícios, principais representantes do que o autor denomina Matemática tradicional, são fortes representantes dessa perspectiva, essa prática, contudo não estimula o desenvolvimento da criatividade matemática.

\footnotetext{
Exercícios desempenham um papel crucial no ensino de matemática tradicional. Ao longo de todo o período em que frequentam a escola, as crianças, em sua maioria, respondem a mais de 10 mil exercícios. Contudo, essa prática não ajuda necessariamente a desenvolver a criatividade matemática (SKOVSMOSE, 2014, p. 16).
}

Esse foco que os exercícios recebem no ensino de Matemática tradicional está relacionado, segundo o autor, ao regime de verdades que a Matemática estabelece. Todas as informações contidas no enunciado são recebidas como se fossem absolutamente precisas e verdadeiras, nada ali pode estar equivocado ou passível de questionamentos. Todas elas são fechadas, exatas e suficientes. "Um exercício define um micromundo em que todas as medidas são exatas, e os dados fornecidos são necessários e suficientes para a obtenção da única e absoluta resposta certa" (SKOVSMOSE, 2014, p. 17).

Por outro lado, o autor destaca três formas em que a matemática produz algum tipo de potencialização dos alunos: o desenvolvimento da inteligência, a maior chance de 
DOI: http://dx.doi.org/10.33238/ReBECEM.2019.v.3.n.2.22536

sucesso pessoal e o papel social da Matemática. No parágrafo seguinte discutimos um pouco mais as três possíveis formas de potencialização apresentadas pelo autor.

Skovsmose (2014) aponta que o conhecimento matemático diante da sociedade está entre os poucos gêneros do conhecimento cuja importância não tem sido questionada ao longo da história, pelo contrário, sempre recebeu reconhecimento e prestígio.

Para os antigos gregos, que buscavam no conhecimento alguma forma de certeza, a matemática tinha um valor especial. Platão sustentava que o conhecimento e a certeza estavam ao alcance do ser humano e a matemática era o exemplo mais notável disso. [...] Tempos depois, com a revolução científica, os poderes da matemática ganharam novo formato. Tornou-se senso comum que as leis da natureza possuem um caráter matemático (SKOVSMOSE, 2014, p. 19).

Ou seja, ainda é muito forte em nossa sociedade a visão de que a Matemática é uma forma superior de potencialização em relação a outras áreas do conhecimento e dessa forma possui maior influência no desenvolvimento da inteligência dos sujeitos.

Em relação à maior chance de sucesso pessoal, muito dessa interpretação está ligada às possibilidades de aplicação da Matemática na sociedade industrial. Tornou-se senso comum que as pessoas com boa formação matemática garantem uma boa posição no mercado de trabalho.

Uma série de atividades praticadas em nossa sociedade está reservada àqueles que tiveram uma boa formação em matemática. A educação matemática funciona, assim, para muitas pessoas, como garantia de boa posição no mercado de trabalho. Isso também é potencialização pessoal (SKOVSMOSE, 2014, p. 20).

Outra forma de potencialização diz respeito à dimensão sociopolítica da Matemática. Nessa discussão Skovsmose (2014) vai tratar da justiça social na Educação Matemática. "Na raiz desse processo, está a expectativa de que a educação matemática pudesse concretamente causar impactos de ordem social e política, ao promover uma visão de mundo diferenciada" (SKOVSMOSE, 2014, p. 20).

Para Skovsmose (2000), as aulas de Matemática estão situadas em dois paradigmas, o paradigma do exercício e o paradigma dos cenários para investigação. Segundo ele podemos definir os paradigmas a partir de algumas características elencadas a seguir:

\section{Paradigma do exercício:}

- Aceita-se como premissa central que existe uma, e somente uma, resposta correta.

- Os dados não são questionados.

- Trabalhos prioritariamente mecânicos de repetição e memorização.

- Utilizam-se os exercícios de forma decisiva para a aprendizagem. 


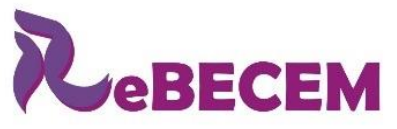

Revista Brasileira de Educação em

Ciências e Educação Matemática

DOI: http://dx.doi.org/10.33238/ReBECEM.2019.v.3.n.2.22536

- O que caracteriza o ensino de Matemática tradicional.

Paradigma dos cenários para investigação:

- Ambientes de investigação, como premissa.

- Os estudantes realizam descobertas.

- Não existem respostas prontas e fechadas.

- Processo repleto de perguntas, explicitação de perspectivas e reflexão.

- O professor deixa de ser o centro das atenções.

Skovsmose (2000) assegura que as aulas baseadas no paradigma do exercício ou em cenários para investigação estão situadas em um determinado contexto em que as ações acontecem. Segundo ele, podem estar situados no contexto da matemática pura, em uma semirrealidade ou podem fazer referências à vida real. A combinação dos dois paradigmas com os três tipos de referências, segundo Skovsmose (2000) dão forma aos ambientes de aprendizagem, como podemos observar no Quadro 1.

Quadro 1: Ambientes de aprendizagem propostos por Skovsmose (2014)

\begin{tabular}{|c|c|c|}
\hline & Lista de Exercícios & Cenários para investigação \\
\hline Referências à matemática pura & $(1)$ & $(2)$ \\
\hline $\begin{array}{c}\text { Referências a uma } \\
\text { semirrealidade }\end{array}$ & $(3)$ & $(4)$ \\
\hline Referências à vida real & $(5)$ & $(6)$ \\
\hline
\end{tabular}

Fonte: Skovsmose (2014, p. 54)

Atividades que fazem referência à matemática pura correspondem a problemas do tipo siga o modelo, acontece apenas o trabalho com operações matemáticas, busca, sobretudo, a fixação de conceitos e conteúdos curriculares. Semirrealidade corresponde a situações possíveis ou não na vida real, mas são situações artificiais. Para Skovsmose (2000) esse é o tipo de referência mais utilizado por autores de livro didáticos, por exemplo. Já nas atividades situadas na vida real, os dados são reais e contribuem para a estruturação, entendimento e resolução do problema.

No ambiente do tipo (1) as atividades são muito comuns em aulas tradicionais de Matemática e pouco exploram a criatividade, uma vez que neste tipo de ambiente, prevalece a mecanização dos procedimentos de resolução, bem como a ideia de que a aprendizagem se dá a partir da repetição de modelos.

As atividades do tipo (2) fazem referência à matemática pura, mas envolvem algum tipo de investigação, desafios a serem cumpridos, relações matemáticas a serem percebidas. Os alunos são incentivados a fazer aproximações, discutir hipóteses, argumentar e debater. 
DOI: http://dx.doi.org/10.33238/ReBECEM.2019.v.3.n.2.22536

O ambiente do tipo (3) é composto por atividades desenvolvidas a partir de situações imaginárias, fictícias, construídas pelo autor da atividade, mas ainda está situada no paradigma do exercício, pois a situação não leva a uma discussão/problematização.

O ambiente do tipo (4) é caracterizado pela presença de atividades que fazem referência também a uma semirrealidade, como o tipo (3), no entanto está relacionado aos cenários para investigação. No entanto ainda existe uma certa limitação nesse ambiente pois mesmo em um processo de investigação, a situação é construída e não verificável.

Quando a atividade apresenta elementos da realidade, mas ainda é solicitada a realização de exercícios com esses dados, sem um direcionamento no sentido de investigação, dizemos que a atividade corresponde ao ambiente do tipo (5). Este ambiente é caracterizado pela presença de exercícios que fazem menção à vida real, como a utilização de gráficos com dados reais, por exemplo (SKOVSMOSE, 2014).

Atividades em que os estudantes são levados a questionar, investigar, refletir, levantar hipóteses, complementar informações, ir a campo e argumentar são consideradas do tipo (6) e são construídas a partir de elementos provenientes da vida real.

Skovsmose (2000) defende que os seis ambientes devem coexistir em sala de aula, pois, dependendo do objetivo do professor e doprofundamento da discussão em cada momento do processo, um ou outro ambiente deve estar presente no trabalho. Ele afirma: "Sustento que a educação matemática deve mover-se entre os diferentes ambientes tal como apresentado na matriz. Particularmente, não considero a ideia de abandonar por completo os exercícios da educação matemática” (SKOVSMOSE, 2000, p. 14).

Acreditamos que apesar da ampla presença de situações financeiras na sociedade, ainda é necessário que a EF oferecida obtenha um caráter crítico, em que os sujeitos não sejam levados pela influência da mídia, que estimula o consumo, incentivando a aquisição de bens móveis e imóveis, construindo verdadeiras “armadilhas" financeiras. Destacamos ainda a importância de tomarmos como base as preocupações da EMC para o trabalho com a EFE para que tenhamos cada vez mais jovens e adolescentes com uma formação crítica no que tange às situações financeiras e que isso reflita em mudanças na estrutura familiar, escolar e social.

A seguir, apresentamos o percurso metodológico do estudo de mestrado do qual realizamos um recorte, bem como o método adotado no presente artigo. 


\section{Método}

O estudo é de natureza qualitativa que, segundo Angrosino (2009), tem se tornado uma proposta consolidada e respeitada em diversas disciplinas e contextos, e não apenas como pesquisa "não quantitativa". Para o autor, a pesquisa visa a abordar o mundo de maneira natural e não em contextos especializados, a fim de descrever, entender e explicar os fenômenos sociais, analisando experiências de indivíduos ou grupos, examinando interações e comunicações entre eles.

O objetivo geral da pesquisa foi compreender possibilidades de abordagem da EF relacionada à MF a partir de um grupo de estudo com professores de Matemática do Ensino Médio. Especificamente os objetivos foram: 1) identificar o que dizem os professores sobre EF e MF bem como as possibilidades de abordagem da EF a partir da relação com a MF; 2) promover reflexões sobre a relação entre EF e MF por meio de um grupo de estudo; 3 ) analisar as possíveis contribuições do grupo de estudo para a prática em sala de aula a partir da experiência dos professores participantes.

Os participantes foram dois professores de Matemática no Ensino Médio. Nosso método foi organizado em cinco etapas: 1) entrevista inicial; 2) grupo de estudo com dois encontros; 3) observação da prática em sala; 4) grupo de estudo para socialização de experiências e 5) entrevista final. No Quadro 2, a seguir, apresentamos as atividades realizadas em cada uma delas.

\begin{tabular}{|c|c|}
\hline Etapas & $\begin{array}{cc} & \text { Atividades } \\
\end{array}$ \\
\hline Entrevista inicial & $\begin{array}{c}\text { Os dois professores são entrevistados individualmente, com o } \\
\text { objetivo de compreender o que conhecem da EF e da MF, bem como } \\
\text { se estabelecem relações entre ambas. }\end{array}$ \\
\hline $\begin{array}{l}\text { Grupo de estudo (primeiro } \\
\text { encontro) }\end{array}$ & $\begin{array}{l}\text { Após a realização das entrevistas individuais, vivenciamos um grupo } \\
\text { de estudo com os professores, no qual no primeiro encontro } \\
\text { apresentamos e discutimos as diversas perspectivas de EF existentes e } \\
\text { as possíveis relações e aproximações com a MF }\end{array}$ \\
\hline $\begin{array}{l}\text { Grupo de estudo (segundo } \\
\text { encontro) }\end{array}$ & $\begin{array}{l}\text { No segundo encontro construímos o planejamento de uma aula em } \\
\text { que atividades de MF possam possibilitar discussões de EF. }\end{array}$ \\
\hline Observação da prática em sala & $\begin{array}{l}\text { Durante essa etapa, realizamos a observação da prática do } \\
\text { planejamento em sala de aula por cada um dos professores. }\end{array}$ \\
\hline $\begin{array}{l}\text { Grupo de estudo (terceiro } \\
\text { encontro - Socialização de } \\
\text { experiências) }\end{array}$ & $\begin{array}{l}\text { No terceiro encontro do Grupo de Estudo, cada participante expõe sua } \\
\text { experiência, identificando pontos em comum, e de que forma as } \\
\text { práticas poderiam ser otimizadas. }\end{array}$ \\
\hline Entrevista Final & $\begin{array}{l}\text { Entrevista individual com os professores para identificar as } \\
\text { contribuições do grupo de estudo para a experiência em sala. }\end{array}$ \\
\hline
\end{tabular}

Fonte: Dados da pesquisa 


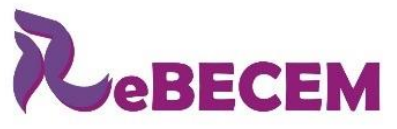

\section{Revista Brasileira de Educação em \\ Ciências e Educação Matemática}

DOI: http://dx.doi.org/10.33238/ReBECEM.2019.v.3.n.2.22536

Para este artigo iremos analisar apenas o momento de prática em sala de aula, com o objetivo de discutir como podemos abordar a EFE no Ensino Médio, a partir da experiência vivenciada pelos professores participantes da pesquisa maior, de mestrado.

Dessa forma, julgamos pertinente apresentar, discutir e justificar a escolha das atividades por nós escolhidas para serem utilizadas no grupo de estudo e que foram retomadas em sala de aula pelos professores participantes. As atividades foram escolhidas por possibilitarem discussões sobre EF, foram utilizadas e indicadas durante um minicurso como atividades de bom potencial para o trabalho com a EF. ${ }^{4}$

Figura 1: Atividade sobre orçamento familiar

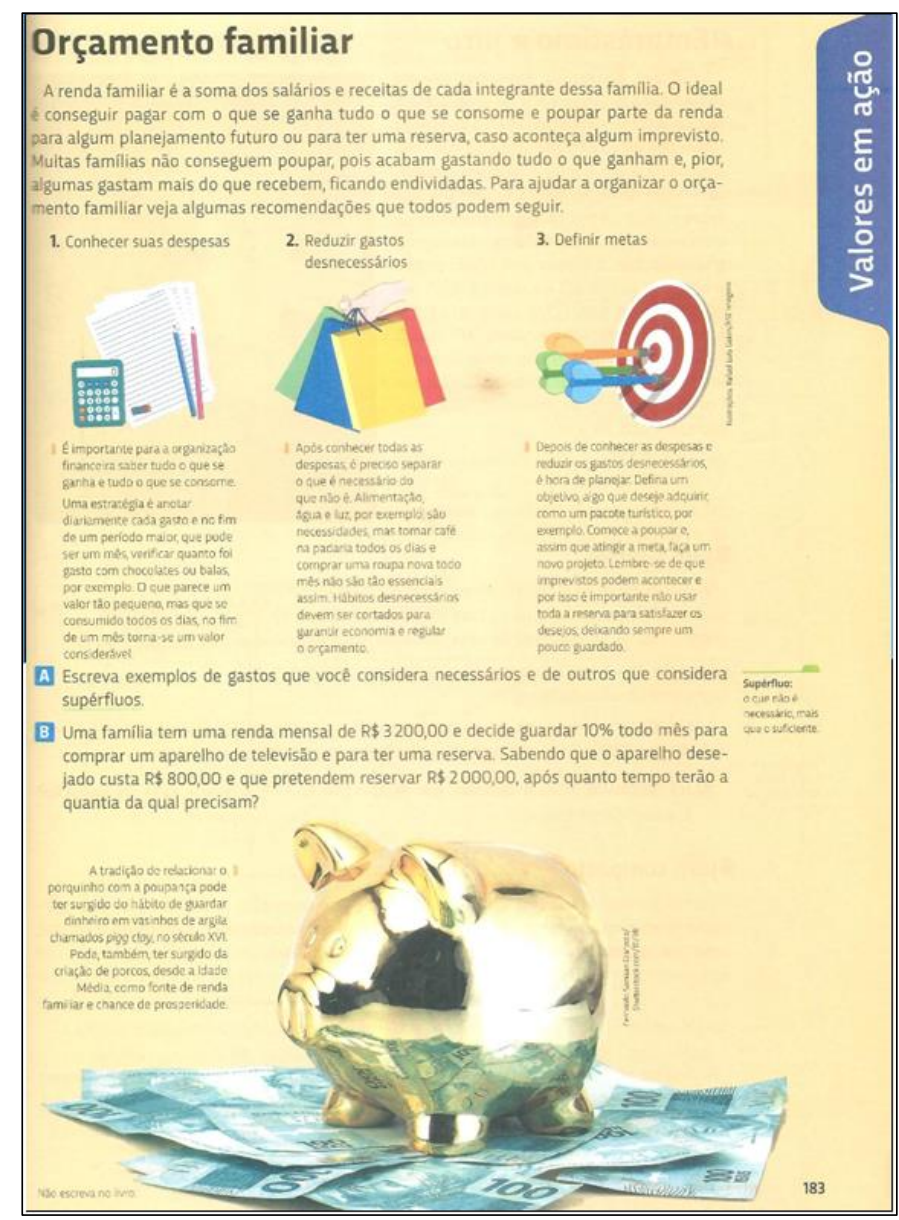

Fonte: Chavante e Prestes (2016, p. 183)

\footnotetext{
${ }^{4}$ Esta atividade foi utilizada durante o minicurso intitulado EDUCAÇÃO FINANCEIRA: como podemos abordar na sala de aula a partir dos ambientes de aprendizagem da Educação Matemática Crítica? Organizado por Azevedo et al., (2018).
} 


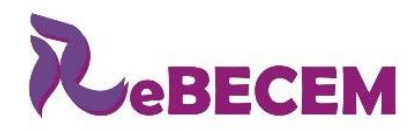

\section{Revista Brasileira de Educação em \\ Ciências e Educação Matemática}

DOI: http://dx.doi.org/10.33238/ReBECEM.2019.v.3.n.2.22536

A atividade da Figura 1, Além de discutir a questão do orçamento familiar, propõe a abordagem em sala de aula de temáticas como comprometimento de renda e o que é necessário ou supérfluo no nosso consumo, pertinentes para um trabalho que conduza os estudantes a uma reflexão crítica a respeito da EF.

Trata-se de uma atividade aberta e que, portanto, não existe uma resposta única, cada estudante pode elencar o que é necessário ou supérfluo para ele. Atividades desse tipo permitem trabalhar a subjetividade da EF, enquanto um estudante considera que comprar um aparelho de celular de última geração é algo necessário, para outro isso pode ser supérfluo. Além disso, a discussão que estas escolhas podem gerar, possibilitam a criação de cenários para investigação.

Figura 2: Atividade sobre compras à vista ou a prazo

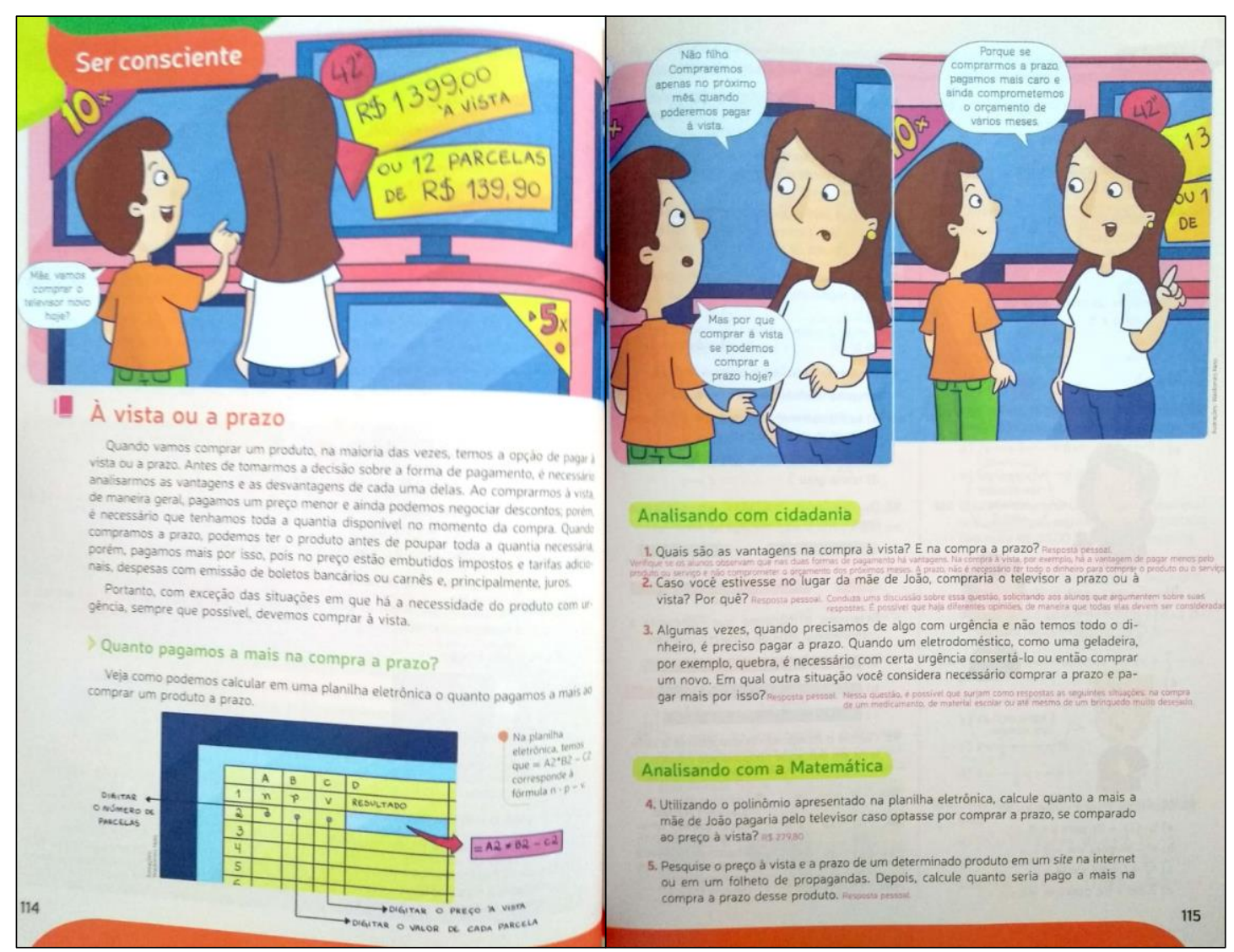

Fonte: Souza e Pataro (2015, p. 114)

Na atividade apresentada a Figura 2, observamos uma discussão sobre compras à vista versus compras a prazo. Trata-se de uma atividade de abertura de capítulo em que provavelmente o autor tem o objetivo de situar o estudante a respeito de discussões econômicas. Na atividade, observamos uma discussão pertinente, quando o autor destaca que: "Antes de tomarmos a decisão sobre a forma de pagamento, é necessário analisarmos 
DOI: http://dx.doi.org/10.33238/ReBECEM.2019.v.3.n.2.22536

as vantagens e as desvantagens de cada uma delas" (SOUZA; PATARO, 2015, P. 114).

E ainda, "com exceção das situações em que há necessidade do produto com urgência, sempre que possível devemos comprar à vista" (SOUZA; PATARO, 2015, P. 114).

Coadunamos com a perspectiva apresentada no início da atividade a respeito da melhor forma de pagamento, pois nem sempre vamos pagar menos por determinado produto, o que devemos fazer é a análise das vantagens e desvantagens de cada situação. Uma das variáveis que interferem nesse processo é o quanto estamos necessitando do produto e isso pode fazer com que paguemos um pouco mais por ele, e isso não faz com que nossa EF seja frágil, o que não pode acontecer é pagarmos sempre mais caro em nossas compras sem realizar a análise crítica da situação.

As disussoes levantadas pelas duas atividades são estreitamente relacionadas dentro do campo da EFE, pois durante a escolha na compra à vista ou a prazo, um dos elementos que devemos levar em consideração é o comprometimento do orçamento familiar se realizamos compras a prazo sem planejamento.

A seguir, apresentamos os resultados encontrados no estudo, no que diz respeito à prática em sala de aula pelos professores participantes.

\section{Resultados}

Em nosso estudo de mestrado contamos com a participação de dois professores de Matemática no Ensino Médio. As aulas foram vivenciadas em turmas do primeiro ano com duração média de duas horas cada. Para fins de caracterizar cada professor, elencamos a seguir profissionais perfil profissional dos participantes, no entanto, é importante destacar que não temos a pretensão de realizar nenhum tipo de comparação entre as práticas e possíveis relações com o tempo de atuação no campo escolar dos participantes.

Quadro 3: Características profissionais dos participantes

\begin{tabular}{|c|c|c|}
\hline & Professor P1 & Professor P2 \\
\hline $\begin{array}{ll}\text { Tempo de } & \text { de } \\
\text { experiência } & \\
\text { profissional } & \\
\end{array}$ & Vinte anos. & Dez anos. \\
\hline $\begin{array}{l}\text { Formação } \\
\text { inicial }\end{array}$ & $\begin{array}{l}\text { Licenciatura em Ciências com } \\
\text { habilitação em Matemática. }\end{array}$ & $\begin{array}{l}\text { Licenciatura em Ciências com habilitação em } \\
\text { Matemática. }\end{array}$ \\
\hline $\begin{array}{l}\text { Formação } \\
\text { continuada }\end{array}$ & $\begin{array}{l}\text { Pós-graduação latu sensu em } \\
\text { Educação Matemática; Pós- } \\
\text { graduação em Neuropedagogia e } \\
\text { Pós-graduação em Aprendizagem } \\
\text { Cooperativa e } \\
\text { Educacional. }\end{array}$ & $\begin{array}{l}\text { Pós-graduação latu sensu em Educação } \\
\text { Matemática. }\end{array}$ \\
\hline
\end{tabular}




\section{$R_{\text {eBECEM }}$}

Revista Brasileira de Educação em

Ciências e Educação Matemática

DOI: http://dx.doi.org/10.33238/ReBECEM.2019.v.3.n.2.22536

\begin{tabular}{|l|l|l|}
\hline $\begin{array}{l}\text { Tempo } \\
\text { trabalho de } \\
\text { escola atual }\end{array}$ & Nove anos. & Um ano. \\
\hline $\begin{array}{l}\text { Organização das } \\
\text { aulas }\end{array}$ & $\begin{array}{l}\text { Acompanha um plano de ação } \\
\text { realizado no início do semestre. } \\
\begin{array}{l}\text { Um roteiro da aula ajuda no } \\
\text { desenrolar da aula (norteia). }\end{array}\end{array}$ & $\begin{array}{l}\text { Atividades sobre o conteúdo a ser abordado, } \\
\text { fichas de exercícios. Elaboração de um } \\
\text { roteiro, exploração do conteúdo, } \\
\text { incorporando no cotidiano do aluno e } \\
\text { aplicação do conteúdo em questões. }\end{array}$ \\
\hline
\end{tabular}

Fonte: Dados da pesquisa

Dentro do campo das temáticas relacionadas à $\mathrm{EF}$, os professores puderam selecionar o tema que seria o fio condutor do trabalho durante a aula. Maiores informações acerca de como se deu o percurso até a seleção dos temas podem ser obtidas na versão completa da dissertação. A seguir apresentamos os planejamentos e as aulas dos professores. Os títulos das seções seguintes se relacionam às temáticas das aulas dos professores.

\subsection{Como o nosso consumo pode influenciar no orçamento familiar?}

O professor organizou a aula a partir de uma atividade sobre orçamento familiar (ver Figura 1), retirada de um livro didático. Com a aula, P1 objetivou discutir como os impostos que pagamos nas compras do supermercado estão relacionadas com a renda familiar e, portanto, como pode interferir no orçamento familiar. Previamente o participante organizou o seguinte roteiro.

Figura 3: Roteiro de aula de P1

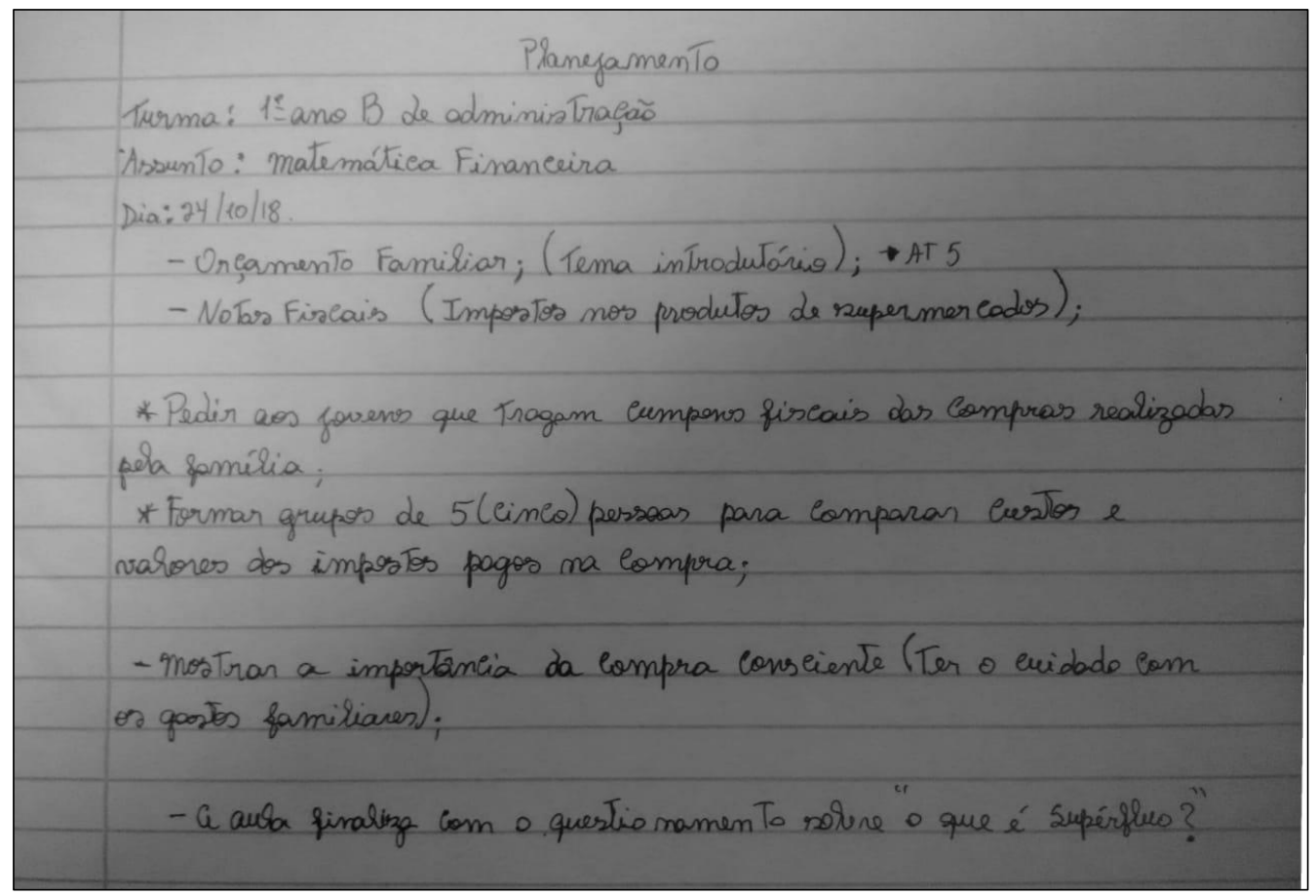

Fonte: Dados da pesquisa 
DOI: http://dx.doi.org/10.33238/ReBECEM.2019.v.3.n.2.22536

O momento inicial da aula corresponde ao mapeamento dos conhecimentos prévios dos estudantes a respeito dos conceitos envolvidos. A fala de uma das estudantes sobre a aplicação dos conhecimentos financeiros no dia a dia nos chamou a atenção. $O$ professor perguntou a respeito do orçamento financeiro, se os estudantes tinham conhecimento da realização por suas famílias, ou se mesmo eles sendo estudantes, também faziam uso deste recurso.

Estudante: "Faz, mas não segue isso, é importante, mas não segue".

A estudante aponta para uma discussão importante: os consumidores, na maior parte das vezes sabem o que é o orçamento familiar, sabem da sua importância para uma vida equilibrada do ponto de vista financeiro e, principalmente, como o consumo de bens ou serviços desnecessários pode comprometer a renda familiar, o que não se sabem, de um modo geral, é como organizar tal orçamento.

Para os estudantes, o principal aspecto que influencia no orçamento familiar é o fato de estudarem em uma escola pública, e mais, como é de tempo integral, ajuda também nas despesas com a alimentação em suas casas. P1 segue com as discussões sobre a forma como os estudantes influenciam no orçamento familiar.

P1: "Vocês conseguem enxergar no dia a dia, que mesmo presos aqui dentro
mesmo assim a gente ainda tem gastos desnecessários?"
Estudante: "Sempre, eu preciso de um sapato? Não. Mas, eu quero um sapato".
Estudante: "Sim, principalmente com as tias do lanche".

Destacamos a fala de dois estudantes, a primeira aponta a compra de um sapato e ela própria reconhece que muitas vezes compra mais por desejo do que por necessidade, o que acontece com a maior parte dos consumidores. Uma das questões que pode levar a esse tipo de consumo, como aponta Bauman (2008), é a influência da mídia e das propagandas, que investem em publicidades que despertam nas pessoas necessidades que, na verdade, são puramente desejos. Os adolescentes e jovens, como usuários diários de redes sociais, onde encontramos muitas dessas propagandas, são uns dos principais alvos desses tipos de campanha.

Outro estudante destaca como a compra de lanches durante o turno escolar pode influenciar no orçamento familiar. De início, podemos pensar que se trata de algo simples, e que na verdade não deve influenciar tanto assim, ou ainda, que se trata de um consumo necessário, pois, afinal os estudantes precisam se alimentar. O que devemos levar em consideração é que a escola oferece lanches e almoço durante os três intervalos entre as aulas, e que o consumo de lanches todos os dias não é tão necessário assim, e se for o 


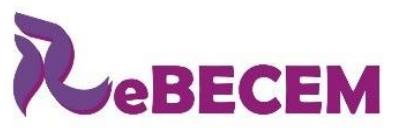

Revista Brasileira de Educação em

Ciências e Educação Matemática

ISSN 2594-9179

DOI: http://dx.doi.org/10.33238/ReBECEM.2019.v.3.n.2.22536

caso de não gostar do lanche oferecido na escola, eles poderiam trazer o próprio lanche de casa, o que sem dúvida, é mais econômico que a compra dos lanches vendidos.

Consideramos importante o fato de os estudantes reconhecerem como seus consumos podem influenciar no orçamento familiar, desde a compra de lanches na escola, até a compra de um sapato que na verdade não é tão necessário assim. No entanto, o que esperamos como resultado da abordagem da EFE, é uma mudança de postura dos estudantes em relação a tais questões.

Diante da discussão sobre o consumo necessário e supérfluo, o professor solicitou que os estudantes realizassem a parte A da atividade, que apresenta a seguinte orientação: "Escreva exemplos de gastos que você considera necessários e de outros que considera supérfluos" (CHAVANTE; PRESTES, 2016, p. 183).

As respostas dos estudantes foram recolhidas por nós, com o objetivo de compreendermos o que, segundo eles, é algo necessário e o que é supérfluo. A partir disso, organizamos o seguinte quadro com algumas das respostas encontradas.

Quadro 4: Respostas dos estudantes sobre gastos necessários e supérfluos

\begin{tabular}{|l|l|}
\hline \multicolumn{1}{|c|}{ Gastos necessários } & \multicolumn{1}{c|}{ Gastos supérfluos } \\
\hline Alimentação & $\begin{array}{l}\text { Lanches em restaurantes e shopping } \\
\text { Açaí frequentemente } \\
\text { Comprar comida à tia do lanche }\end{array}$ \\
\hline Roupas quando realmente precisar & Roupas em excesso \\
\hline Internet & Internet \\
\hline Energia elétrica & \\
\hline Água & \\
\hline Formação escolar & \\
\hline Gás & \\
\hline Saúde & Mudar de aparelhos tecnológicos sempre \\
\hline & Material escolar em excesso \\
\hline & Produtos de beleza \\
\hline
\end{tabular}

Fonte: Dados da pesquisa

Durante o momento de socialização das respostas sobre os gastos necessários e supérfluos, os estudantes discordaram em alguns itens, como por exemplo, sobre internet, por isso ele aparece nas duas colunas do Quadro 4. O que é natural, já que se trata de uma questão de natureza subjetiva, o que corrobora com o que Muniz (2016) defende, e nós concordamos, sobre o trabalho com a EFE gerar aspectos matemáticos e não matemáticos, ou seja, as subjetividades, as tomadas de decisão em função de emoções, desejos, crenças são elementos a serem levados em consideração em discussões sobre EF com estudantes.

Uma das questões que julgamos importante de ser discutida é que o gasto com roupas apareceu também nas duas colunas, como necessário e supérfluo, o que mudou de 
DOI: http://dx.doi.org/10.33238/ReBECEM.2019.v.3.n.2.22536

um caso para o outro foi o excesso, ou seja, para eles a compra de roupas é necessária, mas o excesso é supérfluo. É muito importante essa visão apresentada pelos estudantes, pois o que faz um produto ou serviço se tornar supérfluo é o quanto nós estamos realmente precisando dele ou não. Essa discussão se relaciona ao que Bauman (2008) define como consumo e consumismo, para ele consumo é a satisfação de necessidades fundamentais e consumismo ocorre com os excessos, ou seja, quando se compra por impulso ou quando se compra mais do que se precisa, quando compramos por desejo e não por necessidade. Destacamos essa perspectiva a partir da resposta apresentada por um dos estudantes, como observamos na figura a seguir.

Figura 4: Exemplo de resposta de um estudante sobre gastos necessários e supérfluos

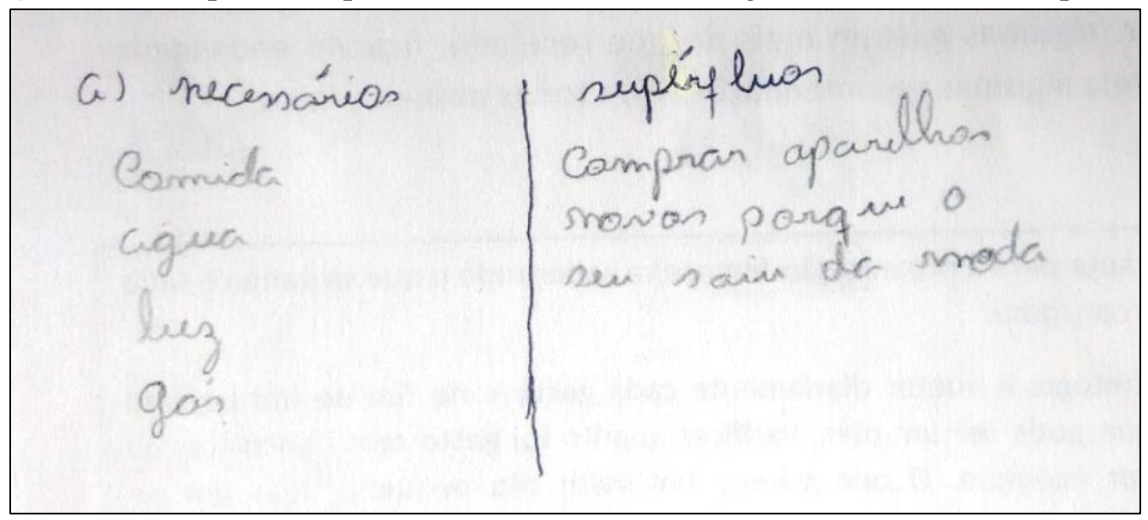

Fonte: Dados da pesquisa

Após a discussão em torno do que é necessário ou supérfluo, o professor conduz a reflexão para a questão dos impostos que pagamos ao consumir algum produto, nesse caso específico, o consumo em supermercados. No roteiro construído durante o grupo de estudo, P1 indicou a solicitação de cupons fiscais de compras realizadas pelas famílias dos estudantes, no entanto, os cupons utilizados na aula foram trazidos pelo próprio professor. Ele conseguiu, em um supermercado da cidade, cupons que os clientes descartam no ato da compra.

P1: "Vocês economizam por um lado [or estudarem em escola pública], mas
assim, por ser público não quer dizer que não tem gasto. Que fique claro que
existe sim, um gasto, mas aqui você gasta uma vez só, com os impostos que
você paga. E essa história de imposto vocês conhecem bem, claro, que nas
planilhas nós não embutimos os impostos. E daqui a pouco nós vamos ver essa
questão dos impostos".

O professor organizou uma aula em que os estudantes conseguiram associar as discussões com sua realidade, perspectiva que é defendida por Skovsmose (2000) em sua teoria da Educação Matemática Crítica (EMC), que o ensino de Matemática consiga levar o estudante a refletir acerca da sua vivência social, utilizando os conhecimentos desta área 
DOI: http://dx.doi.org/10.33238/ReBECEM.2019.v.3.n.2.22536

como ferramenta. A aproximação da Matemática com a realidade também é defendida por Kistemann Jr. (2016), que afirma que o conhecimento matemático precisa despertar no estudante a capacidade de argumentação e segurança para saber lidar com problemas oriundos de suas práticas sociais.

\section{2 À vista ou a prazo, qual a melhor forma de pagamento?}

A discussão da aula ministrada por P2 está em torno das vantagens nas compras à vista ou a prazo. A turma participante é de um primeiro ano do Ensino Médio, assim como a turma de P1. P2 organizou para a aula o roteiro apresentado na figura a seguir.

Figura 5: Roteiro de aula de P1

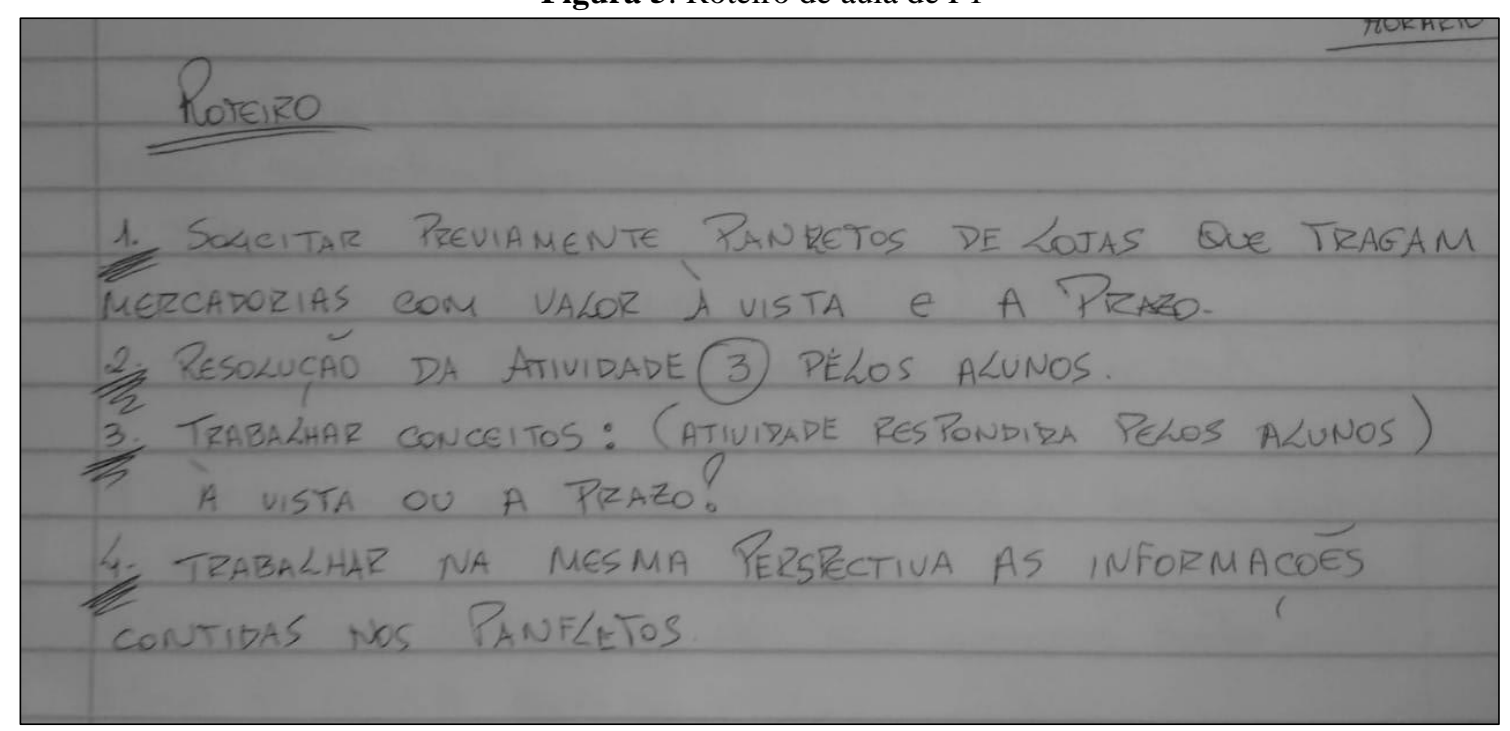

Fonte: Dados da pesquisa

O professor solicitou com antecedência que os estudantes levassem panfletos promocionais de lojas da cidade. O professor orientou os estudantes na resolução da atividade (ver Figura 2) que apresenta uma situação fictícia de compras, em que os personagens devem tomar decisão em relação à forma de pagamento, se compram o produto a prazo e pagam a mais por isso, ou se esperam para juntar a quantia e comprar à vista. Após a resolução individual da atividade, o professor segue para um momento de socialização e discussão das respostas apresentadas.

As questões estão organizadas em dois blocos, o primeiro corresponde à análise com cidadania, e o segundo à análise com Matemática. A primeira pergunta do primeiro bloco é a seguinte: Quais as vantagens na compra à vista? E na compra a prazo?

No geral eles acreditam que a vantagem das compras à vista é o fato de pagarmos menos pelo produto, e que não comprometemos nosso orçamento mensal com as parcelas 
DOI: http://dx.doi.org/10.33238/ReBECEM.2019.v.3.n.2.22536

do produto. Já na compra a prazo, mesmo cientes que pagariam a mais pelo produto, de acordo com a situação que estamos passando, pode ser uma saída, principalmente quando necessitamos do produto com urgência e não possuímos o valor integral para comprar.

O professor apresenta exemplos de pessoas da sua família que de certa forma possuem dificuldade em lidar com as questões de finanças.

P2: "Minha mãe compra um negócio de 100 reais e divide em dez vezes. Ela tem uma conversa, eu pago que nem sinto".

E segue discutindo como a junção dessas "pequenas" parcelas no final do mês podem comprometer o orçamento familiar, mesmo tendo como facilidade a retirada do produto de forma imediata. No entanto, ele se volta para a questão da subjetividade, ou seja, em determinadas situações vamos precisar pagar a mais por determinado produto, tudo depende da necessidade que temos no momento. É importante deixar claro que o fato de sermos educados finananceiramente não significa que sempre vamos levar vantagem financeira na aquisição de determinado produto, pois como o professor destaca, uma das variáveis envolvidas nesse processo é a nossa necessidade, que em alguns casos nos leva a pagar a mais. Entretanto, esse pagar a mais deve acontecer de forma consciente, planejada para que não se torne algo frequente em nossas relações de consumo.

P2: "Vocês percebem que essa situação depende da necessidade. Você só tem que usar essas coisas assim, cartão, quando for necessidade mesmo, só comprar a prazo se for uma coisa de muita necessidade mesmo. Quando existe realmente a necessidade, a compra a prazo é interessante".

Em um segundo momento da aula, o professor solicitou aos estudantes que pesquisassem nos panfletos das lojas situações semelhantes à apresentada na atividade, em que o preço a prazo sofre um aumento em relação ao preço à vista, com um olhar atento para as diferentes estratégias utilizadas na publicidade das lojas.

P2: "Nessa imagem tem uma coisa interessante, a estratégia das 12 parcelas chama a atenção e às vezes a pessoa acha que é por dez. Nos panfletos que vocês trouxeram está cheio disso, ou seja, nas duas últimas parcelas a gente está pagando juros".

Estudante: "Meu tio comprou uma televisão em quase 40 vezes, antes de terminar de pagar ela já tinha quebrado".

Além da necessidade de estar atento ao valor das parcelas, os estudantes apontam a importância da pesquisa de preço em diferentes lojas. E ainda, é necessário que nossas compras sigam um planejamento, pois dessa forma podemos, sim, comprar parcelado e evitar o comprometimento da renda familiar.

Estudante: "A minha mãe foi comprar uma máquina de lavar, ela passou quase um mês pesquisando nos sites todos os dias". 
DOI: http://dx.doi.org/10.33238/ReBECEM.2019.v.3.n.2.22536

Outro estudante apresenta o seguinte relato:

Estudante: "Eu perdi o celular, aí eu fui pesquisar um com uma configuração legal e que coubesse no meu orçamento, aí fui procurar na internet. Eu fiquei vendo os preços, aí peguei anotando os preços e os nomes dos celulares, passei um mês fazendo isso, ele à vista era 600, a prazo, dez vezes de 69, aí eu ia comprar à vista, sendo que meu tio encontrou esse mesmo celular seminovo por 500 e se fosse a vista ainda tinha desconto".

Durante a aula de $\mathrm{P} 2$ podemos encontrar algo semelhante à aula de P1, quando este questionou os estudantes a respeito da realização do orçamento familiar e a resposta foi que ele é feito, mas não é seguido. Já P2, diante da desenvoltura dos estudantes em realção a vatangens da compra à vista questiona os estudantes se eles realmente fazem o que falam.

P2: “O que vocês estão falando, vocês fazem realmente?” Estudante: "Não, eu não faço não, não vou mentir”.

Essa, no entanto é uma questão frequente quando se trata de $\mathrm{EF}$, temos muitas informações na teoria, mas quando partimos para a prática não conseguimos vivenciar efetivamente, uma das motivações que apontamos é a forma superficial que contamos muitas vezes de formação financeira.

Destacamos positivamente o papel do professor na aula, ele não levou nada pronto para os estudantes, eles foram levados a questionar, refletir e dialogar a respeito das vantagens e desvantagens na forma como optamos pelo pagamento. $\mathrm{O}$ formato aberto que empregou à aula permitiu que eles percebessem que para cada um e dependendo da situação em que estão inseridos, o processo de tomada de decisão é antes de tudo subjetivo e não envolve apenas a perspectiva financeira. Além disso, o trabalho com os panfletos de lojas da cidade foi um dos pontos importantes da aula, pois permitiu que as discussões fossem as mais reais possíveis.

\section{Considerações}

Em nosso estudo acerca de possibilidades de abordagem da EF nas aulas de Matemática no Ensino Médio, podemos perceber a importância da atuação do professor como condutor das discussões em sala de aula, pois mesmo não sendo o detentor das melhores e únicas alternativas de tomadas de decisão para os estudantes, é ele que os orienta a perceber que na realidade a melhor opção é algo pessoal e que depende de outros fatores para além dos cálculos da MF. A EF trata-se de algo bem mais complexo, que envolve aspectos como: política, meio ambiente, psicologia, economia, entre outros. 
DOI: http://dx.doi.org/10.33238/ReBECEM.2019.v.3.n.2.22536

Um dos pontos altos que podemos destacar nas duas aulas é o trabalho com material da realidade, P1 utilizou cupons fiscais para análise dos impostos que pagamos em compras de supermercados, já P2 fez uso de panfletos de lojas da cidade para exemplificar algumas estratégias utilizadas pelas lojas para influenciar na decisão de pagamentos à vista ou a prazo. Com isso, podemos perceber que os professores não limitaram suas aulas apenas à realização do proposto na atividade.

Acreditamos que a EF possui um caráter para além da discussão no campo matemático, é preciso que sua abordagem aconteça visando à formação de sujeitos críticos e, para tanto, é importante o desenvolvimento de cenários para investigação durante as aulas, como defende a EMC de Skovsmose (2000). As aulas dos professores também apontam para a necessidade de a EFE debater temas como: relações sociais, tomadas de decisão, demandas de consumo, influências da mídia e das propagandas, dentre outros aspectos.

Além da reflexão crítica que deve ocorrer, destacamos também a importância dos princípios elencados por Muniz (2016), o convite à reflexão, a conexão didática, a dualidade e a lente multidisciplinar fazem com que a EF ganhe forma dentro da sala de aula, e que ao discutirmos a temática também possamos abordar os conteúdos matemáticos, ou não, necessários para fundamentar o processo de tomada de decisão, como aconteceu durante as aulas observadas.

Concluímos, que não existe uma forma única de trabalho para a EF, não só no Ensino Médio, mas em qualquer etapa da Educação, defender uma forma fechada de trabalho com a temática retiraria dela seu caráter crítico. Apontamos a necessidade de mais estudos que investiguem novas e diferentes possibilidades, a partir da prática docente e do conhecimento que os estudantes já possuem a respeito do assunto.

\section{Referências}

ANGROSINO, M. Etnografia e observação participante. 1. ed. Porto Alegre: Artmed, 2009.

AZEVEDO, S. et al. Educação Financeira: como podemos abordar na sala de aula a partir dos ambientes de aprendizagem da Educação Matemática Crítica? In: ENCONTRO DE MATEMÁTICA DO AGRESTE PERNAMBUCANO, 5., 2018, Caruaru. Anais... Caruaru: [s.n.], 2018.

BAUMAN, Z. Vida para consumo: a transformação das pessoas em mercadoria. 1. ed. Rio de Janeiro: Zahar, 2008. 
DOI: http://dx.doi.org/10.33238/ReBECEM.2019.v.3.n.2.22536

CAMPOS, M. Educação Financeira na Matemática do Ensino Fundamental: uma análise da produção de significados. 2013. Dissertação (Mestrado em Educação Matemática) - Instituto de Ciências Exatas, Universidade Federal de Juiz de Fora, Juiz de Fora, 2013.

CHAVANTE, E.; PRESTES, D. Quadrante Matemática. 1. ed.. São Paulo: sm, 2016.

COUTINHO, C. O Professor e o livro didático na abordagem da Educação Financeira. In: ENCONTRO NACIONAL DE EDUCAÇÃO MATEMÁTICA, 12., 2016, São Paulo. Anais... São Paulo: [s.n.], 2016.

COUTINHO, C.; TEIXEIRA, J. Letramento Financeiro: um diagnóstico de saberes docentes. REVEMAT- Revista Eletrônica de Educação Matemática, Florianópolis, v.10, n.2, p. 1-22, 2015.

KISTEMANN Jr, M. Uma Discussão sobre a Base Nacional Curricular Comum (Bncc) e o tema integrador "Consumo e Educação Financeira" e o Currículo de Matemática. In: ENCONTRO NACIONAL DE EDUCAÇÃO MATEMÁTICA, 12., 2016, São Paulo. Anais... São Paulo: [s.n.], 2016.

KISTEMANN Jr, M.; ALMEIDA, D.; RIBERO, I. Uma experiência com Educação Financeira de jovens indivíduos consumidores no PRÓBIC-JR-FAPEMIG/UFJF. Revista Paranaense de Educação Matemática, Juiz de Fora, v. 6, n. 10, p. 223-245, jan./jun. 2017.

MUNIZ, I. Educação Financeira e a sala de aula de Matemática: conexões entre a pesquisa acadêmica e a prática docente. In: ENCONTRO NACIONAL DE EDUCAÇÃO

MATEMÁTICA, 12., 2016, São Paulo. Anais... São Paulo: [s.n.], 2016.

MUNIZ, I.; JURKIEWICZ, S. Educação Econômico - Financeira: uma nova perspectiva para o Ensino Médio. In: CONGRESSO IBEROAMERICANO DE EDUCAÇÃO MATEMÁTICA, 7., 2013, Montevideo. Anais... Montevideo: [s.n.], 2013.

OLIVEIRA, A. Educação Fiananceira: como está sendo abordada nos $4^{\circ}$ e $5^{\circ}$ anos do Ensino Fundamental? In: ENCONTRO BRASILEIRO DE ESTUDANTES DE PÓS-GRADUAÇÃO EM EDUCAÇÃO MATEMÁTICA, 20., 2016, Curitiba. Anais... Curitiba: [s.n.], 2016.

OLIVEIRA, A. Educação Financeira nos Anos Iniciais do Ensino Fundamental: como tem ocorrido na sala de aula? 2017. Dissertação (Mestrado em Educação Matemática e Tecnológica) - Centro de Educação, Universidade Federal de Pernambuco, Recife, 2017.

PESSOA, C. Educação Financeira na Perspectiva da Educação Matemática Crítica em Livros Didáticos de Matemática dos Anos Finais do Ensino Fundamental. In: ENCONTRO NACIONAL DE EDUCAÇÃO MATEMÁTICA, 12., 2016, São Paulo. Anais... São Paulo: [s.n.], 2016.

PESSOA, C.; MUNIZ, I.; KISTEMANN Jr, M. Cenários Sobre Educação Financeira Escolar: entrelaçamentos entre a pesquisa, o currículo e a sala de aula de Matemática. EM TEIA Revista de Educação Matemática e Tecnológica Iberoamericana, Recife, v. 9, n. 1. 2018.

SANTOS, T.; PESSOA, C. Educação Financeira na perspectiva da Educação Matemática Crítica: uma reflexão teórica à luz dos ambientes de aprendizagem de Ole Skovsmose. BoEMBoletim online de Educação Matemática, Joinville, v.4, n.7, p. 23-45, dez. 2016.

SILVA, A.; POWELL, A. Um Programa de Educação Financeira para a Matemática Escolar da Educação Básica. In: ENCONTRO NACIONAL DE EDUCAÇÃO MATEMÁTICA, 11., 2013, Curitiba. Anais... Curitiba: [s.n.], 2013. 
DOI: http://dx.doi.org/10.33238/ReBECEM.2019.v.3.n.2.22536

SILVA, A.; POWELL, A. Educação Financeira na Escola: A perspectiva da Organização para Cooperação e Desenvolvimento Econômico. Boletim GEPEM, Juiz de Fora, v. 1, n. 66, p. 0319, jan./jun. 2015.

SOUZA, J.; PATARRO, M. Vontade de saber matemática. 3. ed.. São Paulo: FTD, 2015.

SKOVSMOSE, O. Cenários para investigação. Bolema, Rio Claro, v. 13, n. 14, p. 66-91, 2000.

SKOVSMOSE, O. Um convite à Educação Matemática Crítica. 1. ed. São Paulo: Papirus, 2014.

Recebido em: 31 de maio de 2019.

Aceito em: 17 de agosto de 2019. 